\title{
Hatchability of Selected Commercial Artemia Strains Using Waters from Selected Saline Crater Lakes of Western Uganda
}

\author{
Mujibu Nkambo* \\ Aquaculture Research and Development Center-Kajjansi, National Fisheries Resources Research Institute \\ (NaFIRRI),P O box 530, Kampala, Uganda \\ Matthew Mwanja \\ Aquaculture Research and Development Center-Kajjansi, National Fisheries Resources Research Institute \\ (NaFIRRI),P O box 530, Kampala, Uganda
}

John S Balirwa

National Fisheries Resources Research Institute (NaFIRRI)

P O box 343, Jinja, Uganda

Sauda Nayiga

Faculty Of Laws, Islamic University In Uganda (IUIU)

P O box 2555, Mbale, Uganda

Fredric W Bugenyi

Department of Biological Sciences, College of Natural Sciences (CONAS),

Makerere University, Kampala, P. O. Box 7260, Uganda

The research was funded by National Agricultural Research Organisation (NARO) of Uganda.

\section{Abstract}

Hatchability of Artemia strains; Artemia franciscana from Great Salt Lake (GSL), A. franciscana from salt ponds in Vin Chao (VC), Chinese strain (Chinese), TUZ Parthenogetic Artemia from Kazakhstan (TUZ) and Parthenogenetic Artemia strain from Siberia (PAS) was examined using waters from lakes Katwe, Mururmuri, Bunyampaka, Bagusa and Maseche. The study purpose was to identify the best performing Artemia strain as well as the best suited saline crater lakes in Western Uganda for Artemia production based on hatchability. Artemia cysts were hatched under conditions described by Van Stappen (1996) in fabricated Artemia hatching cones at a salinity of $40 \mathrm{ppm}$, temperature of $27 \pm 2^{\circ} \mathrm{C}$, and light of 2000lux. Hatchability was monitored after 24 hour and 48hour of incubation. Artemia franciscana $(\mathrm{VC})$ had significantly higher hatching percentage than all tested strains (P-value $<0.05)$. Lakes Katwe, Bunyampaka and Maseche waters presented the highest hatching percentages therefore are best suited for Artemia production.

Keywords: Artemia, Hatching percentage, saline crater lakes

DOI: $10.7176 / \mathrm{JNSR} / 9-18-05$

Publication date:September $30^{\text {th }} 2019$

\section{Introduction}

Artemia is commonly referred to as a brine shrimp belonging to the genus Artemia (Wurtsbaugh and Gliwicz 2001) and order Anostraca (Ben Naceur, Jenhani et al. 2012). They are micro crustaceans reported to inhabit extremely saline water environments including inland water bodies and coastal solar salt works (Gajardo and Beardmore 2012; Ogello, Kembenya et al. 2014; Sui, Deng et al. 2014). The use of these micro crustaceans as an important larval food for fish dates way back from the 1930s (Bengtson, Leger et al. 1991). Artemia has been reported to be an excellent live food in the aquaculture industry both in fish a crustacean culture (Makridis and Vadstein 1999; Marini 2002). Artemia's high nutritive value, ease in handling(Bengtson, Leger et al. 1991), adaptability to diverse environments and geographical regions, short generation time, high fecundity, and ability to grow at high densities are among the factors put forward for its wide use (Lavens, Tackaert et al. 1986; Soundarapandian and Saravanakumar 2009 ). Uganda is one of the many African countries currently experiencing very low survivals in fish hatcheries (Mwanja, Rutaisire et al. 2015). Lack of a suitable starter feed is one of the probable factors for the reported low survival in Ugandan fish hatcheries. A few commercial hatcheries have used Artemia as a live starter feed in Ugandan hatcheries with lots of success in improving hatchery survival as it has been in many other countries world-wide. The current biggest impediment to use of Artemia in Ugandan hatcheries is reported to be the high cost of imported Artemia cysts (Nkambo, Bugenyi et al. 2015b). The cost of imported Artemia cysts has continued to increases since the 1950s and by the mid seventies Artemia prices were reported to range between 50 to 100US Dollars per kg (Bengtson, Leger et al. 1991). Many developing countries can hardly afford this very expensive imported Artemia. Uganda being endowed with a number of hyersaline lakes which are reported habitats 
for Artemia (Ben Naceur, Jenhani et al. 2012; Gajardo and Beardmore 2012), exploration of possibilities for production of local Artemia resources can be one way of availing cheap affordable Artemia resources to Ugandan hatcheries. If successfully produced, cheap local Artemia resources could result in its frequent use hence lead to improved survival in hatcheries and enhanced aquaculture production. In a drive towards exploring possibilities for production of local Artemia resources, several saline crater lakes have been surveyed with no local Artemia resources so far been found (Nkambo, Bugenyi et al. 2015a).

In the absence of local Artemia strains, domestication of commercial strains using waters from these hypersaline environments as has been successfully done elsewhere offers another realistic option for production of cheaper Artemia resources. Artemia being highly osmotolerant (Ben Naceur, Jenhani et al. 2012), it is able to adapt to a diverse range of extreme environmental conditions (Gajardo and Beardmore 2012). A classical example of such domestication is Artemia franciscana currently being artificial produced in salt ponds in Vietnam (Kappas, Abatzopoulos et al. 2004; Sui, Deng et al. 2014). Its controlled inoculation in salt ponds is reported to play a role in management of salt pond ecosystems (Sui, Deng et al. 2014). Artemia populations have also been inoculated in salt pans as a biological control for algal blooms, thereby resulting into improved salt quality (Hajirostamloo and Pourrabbi 2011). Use of waters from these hypersaline environments in Uganda to break diapauses and cause hatching of selected commercial Artemia strains is one of the crucial steps towards identifying suitable strains for domestication. Therefore the purpose of this study was to identify the best performing commercial Artemia strain in terms of hatchability and as well as the best suited lake among the selected saline crater of western Uganda for Artemia production. In this study, a strain found to show the highest hatchability shall be considered the best performing while the lake whose waters were used in a hatching experiment which showed the highest hatchability was considered the best suited lake. In this study hatchability of Artemia cysts was defined as the proportion in percentages of Artemia cysts which have been able to break diapauses to give live nauplii in comparison to the total number of cysts incubated.

\section{Materials and Methods}

Artemia hatching unit was fabricated using conical chicken drinkers which were modified to have a tap at the bottom for controlling the water volumes in these cones. These were supported in holes drilled on a $2 \mathrm{~m}^{2}$ surface area, $1 \mathrm{~m}$ above the ground table. All the water samples used in the hatchability experiments were filtered using a series of sieves of $200 \mu \mathrm{m}, 100 \mu \mathrm{m}$ and $50 \mu \mathrm{m}$ to remove the thick algal biomass and other possible predators to the Artemia nauplii. Artemia is reported to be defenseless in nature, prone to destruction by a wide range of predators and therefore only where predators are excluded (Jennings and Whitaker 1941; Kumar and Babu 2015). The salinity in all the used water samples was reduced to $40 \mathrm{mg}^{-1}$ by diluting using filtered fresh water from kajjansi (salinity of $0 \mathrm{mg}^{-1}$ ). The $\mathrm{pH}$ of the different water samples after dilution was recorded.

The tested Artemia strains (Artemia franciscana from Great Salt Lake (GSL), A. franciscana artificially produced from salt ponds in Vin Chao, Vietnam (VC), Chinese strain (Chinese), TUZ Parthenogetic Artemia from Kazakhstan (TUZ) and Parthenogenetic Artemia strain from Siberia (PAS)) were obtained from the Artemia reference Center at Gent University, Belgium, Salt Research Institute of China of China Salt Industry Corperation, China and Can Tho University, Vietnam.

Artemia cysts were hatched under conditions described by Van Stappen (1996). $2 \mathrm{~g}$ of cysts of each of the five (5) tested Artemia strain were place in an Artemia hatching fabricated cone containing 2litres of saline water (40ppt) from each of the five selected saline crater lakes of Western Uganda. The temperature in each of the hatching cones was maintained at $27 \pm 2{ }^{\circ} \mathrm{C}$ using thermostat heaters $(220-240 \mathrm{~V}, 200 \mathrm{~W}, 30 \mathrm{~cm}$, Sera Precision) while the $\mathrm{pH}$ in each of the hatching cone was left at the measured $\mathrm{pH}$ of each of the lake waters. The whole experimental set was supplied with light at 2000luxs, with continuous aeration using air stones connected to a compressor. Three replicates using water samples from each of the selected saline Crater Lake were made for each Artemia strain. After a 24 hour and 48 hour incubation period, three (3) sub-samples of $0.25 \mathrm{ml}$ were taken from each cone to monitor the hatchability. Hatchability is this study was used to refer to the hatching percentage. The number of nauplii, embryos and un-hatched cysts of the pooled sample $(1 \mathrm{ml})$ were counted under a binocular light microscope (Leica DM750). The hatching percentage was calculated as follows:

Hatching Percentage (\%) = Nauplii/ (Nauplii+embryos+ un-hatched cysts) X100\%

Since some of the water quality parameters like Dissolved oxygen, ionic rates, alkalinity and $\mathrm{pH}$ which have been reported to affect hatchability(Sui, Deng et al. 2014) are thought to vary with seasons in these lakes where water samples used in hatchability experiments were collected, these experiments done for both the dry and wet season.

Statistical analysis was conducted on the hatching percentages of the different Artemia strains using water samples collected from the different lakes in the different seasons, hatchability of the different strains using water samples from the different lakes and the hatching percentage of the different strains in water samples from a selected lake using ms excel 2007. Significant differences among the water sample treatments were determined using a two- sample t-test, at $\mathrm{P}<0.05$. The $\mathrm{p}$-values were obtained using the calculated $\mathrm{t}$-values from student $\mathrm{t}$-test 
distribution tables.

\section{Results}

Both in the dry and wet season, water samples from lakes Bagusa and Bunyampaka were found to have the highest conductivity at the time of sample collection. Lake Bagusa dry and wet season water samples were found to have the highest dissolved oxygen levels after dilution while Lake Murumuri dry and wet season samples had the lowest levels of dissolved oxygen after dilution. All the collected water samples remained alkaline after dilution with dry and wet season water samples from lakes Murumuri and Maseche having the highest $\mathrm{pH}$ ranges (Table 1).

Unlike waters samples from Bunyampaka, Murumuri and Maseche which formed much foam after 12hours of aeration, water samples from lakes Bagusa and Katwe had little foam. On observation under a light microscope no nauplii was observed in all the hatching cones for all the cyst strains after 12 hours of aeration and incubation. On sampling after 48hours, all the hatching cones were found to have nauplii being dominated by nauplii with 3 thoracopods (Instar I) with some ciliates (Table 2).

For all the tested Artemia strains there was no significant difference in the hatching percentages between water samples collected in the dry and wet season (P-value $>0.05)$. In all the collected water samples from all the selected lakes in both the dry and wet season, Artemia franciscana from salt pond in Vietnam (VC) was found to have a significantly higher hatching percentage in comparison to all the other tested strains $(\mathrm{P}$-value $<0.05)$. Although less than VC, Artemia franciscana from the Great Salt Lake (GSL) and Chinese Artemia strains (Chinese) were found to have significantly higher hatching percentages than Parthenogenetic Artemia from Siberia (PAS) and Parthenogenetic Artemia from Kazakhstan (TUZ). There was no significant difference in the hatching percentages of Artemia franciscana from the Great Salt Lake (GSL) and Chinese Artemia strain when tested in the different collected water samples. Parthenogenetic Artemia from Siberia (PAS) and Parthenogenetic Artemia from Kazakhstan (TUZ) were found to have the lowest hatching percentages. With the exception of the trials with Parthenogenetic Artemia from Siberia (PAS) and Parthenogenetic Artemia from Kazakhstan (TUZ), water samples from lakes Katwe, Bunyampaka and Maseche generally had higher hatching percentages (Table 3).

\section{Discussion}

The reported physico-chemical parameters in the different sampled lakes were comparable to those reported in earlier limnological studies of the saline crater lakes of western Uganda by Nkambo, Bugenyi, et al., (2015a). The foam observed in all the hatching cones (Table 2) during the incubation and aeration process might be attributed to the used lake water samples being high in dissolved organic matter contributed to by the thick algal biomass in these lakes (Nkambo, Bugenyi et al. 2015a). Unique cynobacteria and algal blooms have been reported to occur in these alkaline saline lakes (Mungoma 1990; Jones and Grant 1999; Matagi 2004; Hadgembes 2006). The lack of hatched nauplii after the first 24 hours in all the hatching cones could be attributed to slow cyst hydration caused by the foam in the different hatching cones. The foam formed on aeration in the different hatching cones meant that many of the inoculated cysts were held up in the foam before getting in contact with water hence took long to be well hydrated. Critical hydration levels have been reported to limit metabolic activities in A. franciscana cysts (Drinkwater and Crowe 1991) and this in effect prevents hatching by ensuring Artemia cyst diapause is not deactivated until after the cysts are well hydrated. Artemia cysts swell and become spherical after 1 to 2 hours after inoculation in seawater. After 12 to 20 hours of hydration, cyst shells burst leaving the embryo in its hatching membrane visible (FAO 1996). On rehydration diapauses are deactivated with cysts suddenly undergoing embryonic development (Truchan and Deyrup-Olsen 1993; Drewes 2006; Podrabsky and Hand 2015). It is reported that active metabolisms resumes in the cyst after $60 \%$ hydration (FAO 1996). In studies of the effect of hydrogen peroxide treatment in Artemia cysts of different geographical origin, hydration levels were found to have an effect on hatching of San Franscisco bay (A. franciscana) cysts (Van Stappen, Lavens et al. 1998). The observed ciliates after 48hours of incubation might have been eggs of zooplanktons which were able to go through the filters and hatched during the incubation process.

Salinity, temperature, food availability and ionic composition have been reported to play a vital role in determining the occurrence of Artemia (Gajardo and Beardmore 2012; Sui, Deng et al. 2014). Since salinity, and temperature were regulated and kept the same in all cones in this present experiment, this leave ionic composition as one of the factors which could affect hatchability in this current experiment. Effective reproductive isolation in some Artemia populations has been reported to be due to the different tolerance to ionic compositions (Munoz, Amat et al. 2013). In a study of Artemia occurrence, salinity and ionic rates in saline crater lakes of Western Uganda by Nkambo, Bugenyi et al., (2015b), there were no significant difference in the ionic rates of the water samples collected from these saline craters in the dry and wet season. This could be the reason to explain the lack of significant difference in the hatching percentages between the collected wet and dry season water samples from all the studied lakes. Although Artemia has been reported to be extremely tolerant to environmental parameters like salinity, pH among others (Ben Naceur, Jenhani et al. 2012; Gajardo and Beardmore 2012), it was reported to be relatively intolerant to certain ions like potassium (Jennings and Whitaker 1941; Gajardo and Beardmore 2012). 
Artemia franciscana Kellogg (1906) is reported be among the most widely distributed brine shrimp (Camargo, Durán et al. 2005; Munoz, Amat et al. 2013), adapted to live in a broad diversity of isolated water bodies with varying ranges of water chemistry (Munoz, Amat et al. 2013). Genetic and morphological variations have been reported in $A$. franciscana populations with an ability to adapt to local ionic compositions of their environments(Munoz, Amat et al. 2013). It is reported to have proven a good inoculums in many new environments (Sui, Deng et al. 2014). These could be the very reasons to explain the significantly higher hatching percentage of A. franciscana from salt pond in Vietnam (VC), and the GSL strain compared to the other tested strains. $A$. franciscana from salt pond in Vietnam (VC) having a significantly higher hatching percentage than the GSL strain despite both being strain of $A$. franciscana could be because $A$. franciscana from salt pond in Vietnam (VC) is already adapted to salt pond water environments.

Water samples from lake Murumuri which is reported to be carbonate-chloride dominated lake (Nkambo, Bugenyi et al. 2015a) presented some of the lowest hatching percentage yet Artemia is reported to prefer carbonate-chloride dominated waters (Camargo, Durán et al. 2005). Lakes Katwe, Bunyampaka, and Maseche despite being carbonate-sulphate dominated (Nkambo, Bugenyi et al. 2015a), water samples collected from these lakes presented the highest hatching percentages. Even though alkaline condition have been reported to be the preferred $\mathrm{pH}$ conditions for hatching, extreme alkaline conditions might not be suitable for Artemia cyst hatching. In an experiment relating $\mathrm{pH}$ with hatching success, cysts of Triops cancriformis a Crustacean Branchiopod were not able to hatch at $\mathrm{pH}$ values of 9 and above (Schonbrunner and Eder 2006). A pH range of 8-8.5 has been reported as the range for optimum Artemia cyst hatching (FAO 1996; Marini 2002; Ben Naceur, Jenhani et al. 2009; Zheng, Jeswin et al. 2015). A similar $\mathrm{pH}$ range of 7-8.5 is reported to be optimum $\mathrm{pH}$ range where maximum hatchability levels were observed in diapausing freshwater fairly shrimp Streptocephalus dichotomus (Baird) (Amutha and Subramanian 2008). The very low hatching percentages in water samples from Lake Murumuri might have been caused by the $\mathrm{pH}$ of these waters being very high above the reported optimal hatching $\mathrm{pH}$. $\mathrm{pH}$ has also been reported as one of the key environmental parameters which affect growth and survival of Artemia under culture conditions (Soundarapandian and Saravanakumar 2009 ).

\section{Conclusion}

Based on hatching percentages from the present study, A. franciscana from salt pond in Vietnam (VC), followed by Artemia franciscana from the Great Salt Lake (GSL) and the Chinese strain in that order were the best performing strains. Water samples from lakes Katwe, Bunyampaka and Maseche presented the highest hatching percentages giving an indication that waters samples from these lakes might be best suited for Artemia production.

\section{Recommendation}

It is recommended that survival and growth performance assessment be included among the different parameters used in assessing performance of the different Artemia strains in the subsequent trails. Since decapsulation has been reported to increase hatchability (Hammer 1986), similar trial should be done using decapsulated cysts.

\section{Acknowledgement}

Special thanks and acknowledge is reserved for the National Agricultural Research Organisation (NARO), National Fisheries Resources Research Institute (NaFIRRI), Kajjansi Aquaculture Research and Development Center (KARDC), Department of Biological Science, Makerere University, Uganda Wild Life Authority and their staff in Queen Elizabeth National Park; and Katwe-Kabatoro Community for the various support offered will carrying out this research.

\section{References}

Amutha, C. and P. Subramanian (2008). "Conducive conditions for the hatchability of freshwater fairy shrimp Streptochepalus dichotomus (Baird) diapausing cysts." Biochemistry and Cell Arch. 8(2): 245-248.

Ben Naceur, H., A. B. R. Jenhani, et al. (2009). "NOTES ON GEOGRAPHIC DISTRIBUTION, New distribution record of the brine shrimp Artemia (Crustacea, Branchiopoda, Anostraca) in Tunisia." Check List 5(2): 281288.

Ben Naceur, H., A. B. R. Jenhani, et al. (2012). "Impacts of salinity, temperature and pH on the morphology of Artemia (Branchiopoda: Anostraca) from Tunisia." Zoological studies 51 (4 ): 453 - 462.

Bengtson, A. D., P. Leger, et al. (1991). Use of Artemia as a food source for Aquaculture. Artemia Biology. R. A. Browne, P. Sorgeloos and C. N. A. Trotman. Boca Raton, FL, CRC Press.

Camargo, W. N., G. C. Durán, et al. (2005). "Determination of biological and physicochemical parameters of Artemia franciscana strains in hypersaline environments for aquaculture in the Colombian Caribbean." Saline Systems 1(9).

Drewes, C. (2006). Quantitative investigations of hatching in brine shrimp cysts. Proceedings of the 27th Workshop/Conference of the Association for Biology Laboratory Education (ABLE), Association for 
Biology Laboratory Education (ABLE).

Drinkwater, E. L. and H. J. Crowe (1991). "Hydration state, Metabolism and Hatching of Mono Lake Artemia cysts." Bio. Bull 180: 432-439.

FAO (1996). Use of Cysts. Manual on the production and Use of live food for aquaculture. P. Lavens and P. Sorgeloos. Rome, FAO. 361.

Gajardo, G. M. and J. A. Beardmore (2012). "The Brine Shrimp Artemia: Adapted to Critical Life Conditions." Frontiers in Physiology 3: 185.

Hadgembes, T. (2006). Environmental Threats to East African Saline Lakes and their likely conservation strategies. Addis Ababa, Ethiopia, academia.ed.

Hajirostamloo, M. and R. Pourrabbi (2011). "Genetic Differentiation of Artemia franciscana in a New Environment (Iran)." World Journal of Zoology 6(1): 16-21.

Hammer, U. T., Ed. (1986). Saline Ecosystems of the World., Dordrecht Publishers.

Jennings, R. H. and D. M. Whitaker (1941). "The Effect of Salinity upon the Rate of Excystment of Artemia." Biological Bulletin 80(2): 194-201.

Jones, E. B. and W. D. Grant (1999). Microbial diversity and ecology of soda Lakes of East Africa. Microbial Biosystems: New Frontiers, Halifax, Canada, Atlantic Canada Society for Microbial Ecology.

Kappas, I., T. J. Abatzopoulos, et al. (2004). "Genetic and reproductive differentiation of Artemia franciscana in a new environment." Marine Biology 146: 103-117.

Kumar, G. R. and D. E. Babu (2015). "Effect of Light, Temperature and Salinity on the growth of Artemia." International Journal of Engineering Science Invention 4(12): 07-14.

Lavens, P., W. Tackaert, et al. (1986). "International Study on Artemia *. XLI. Influence of culture conditions and specific diapause deactivation methods on the hatchability of Artemia cysts produced in a standard culture system." MARINE ECOLOGY - PROGRESS SERIES 31: 197-203.

Makridis, P. and O. Vadstein (1999). "Food size selectivity of Artemia franciscana at three developmental stages." JOURNAL OF PLANKTON RESEARCH 21(11): 2191-2201.

Marini, F. (2002). "The Breeder's Net: Artemia Nauplii as a Food Source." Advanced Aquarist 1(1).

Matagi, S. V. (2004). "A biodiversity assessment of the Flamingo Lakes of eastern Africa." Biodiveristy 5(1): 13 $-26$.

Mungoma, S. (1990). "The alkaline, saline lakes of Uganda: a review." Hydrobiologia 208: 75 - 80.

Munoz, J., F. Amat, et al. (2013). "Bird migratory flyways influence the phylogeography of the invasive brine shrimp Artemia franciscana in its native American range." Peer J 7(1): 1-28.

Mwanja, M., J. Rutaisire, et al. (2015). "Current fish hatchery practices in Uganda: The potential for future investment." International Journal of Fisheries and Aquatic Studies 2(4): 224-232.

Nkambo, M., F. W. Bugenyi, et al. (2015). "Limnological Survey of the Alkaline, Saline crater lakes of Western Uganda." Journal of Natural Science Research 5(2).

Nkambo, M., F. W. Bugenyi, et al. (2015). "Artemia Occurrence, Salinity and Ionic Rates in Saline Crater Lakes of Western Uganda." International journal of Ecosystems 5(2): 59-65.

Ogello, O. E., E. Kembenya, et al. (2014). "The occurrence of the brine shrimp, Artemia franciscana (Kellog 1906) in Kenya and the potential economic impact among Kenyan coastal communities." International Journal of Fisheries and Aquatic Studies 1(5): 151 - 156.

Podrabsky, E. J. and C. S. Hand (2015). "Physiological strategies during animal diapause: lessons from brine shrimp and annual killifish." Journal of Experimental Biology(218): 1897-1906.

Schonbrunner, M. I. and E. Eder (2006). "pH-related Hatching success of Triops cancriformis (Crustacea: Branchiopoda:Notostraca)." Hydrobiologia 563(1): 515-520.

Soundarapandian, P. and G. Saravanakumar (2009). "Effect of different salinities on the survival and growth of Artemia Spp. ." Current Research Journal of Biological Sciences 1 (2 ): 20 -22.

Sui, L., Y. Deng, et al. (2014). "Impact of acidification on hatchability, survival and reproduction of Artemia parthenogentica and Artemia franciscana in salt ponds, Bohai bay, China." Chinese Journal of Oceanography and Limnology 32(1): 81-87.

Truchan, C. L. and I. Deyrup-Olsen (1993). Experimental Design and Testing: hatching and development in brine shrimp. Tested Studies for labaratory teaching, Association of Biology Laboratory Education (ABLE).

Van Stappen, G., P. Lavens, et al. (1998). "Effects of Hydrogen Peroxide treatment in Artemia cysts of different Geographical origin." Arch. Hydrobiol. Spec. Issues Advanc. Limnol. 52: 281-296.

Wurtsbaugh, A. W. and Z. M. Gliwicz (2001). Limnological Control of Brine shrimp population dynamics and cyst production in the Great Salt Lake, Utah. Saline Lakes. J. M. Melack, R. Jellison and B. D. Herbst, Kluwer Academic Publishers. 466: 119-132.

Zheng, C.-q., J. Jeswin, et al. (2015). "Detrimental effect of CO2-driven seawater acidification on a crustacean brine shrimp, Artemia sinica." Fish \& Shellfish Immunology 43(1): 181-190. 
Tables

Table 1: Water quality physical characteristics (salinity, Dissolved Oxygen and pH) of the collected waters samples from the selected lakes

\begin{tabular}{lllllll}
\hline water sample & $\begin{array}{l}\text { Salinity } \\
\text { Dilution(mg/l) }\end{array}$ & Before & \multicolumn{2}{l}{$\begin{array}{l}\text { Dissolved Oxygen after } \\
\text { dilution to 40ppm (mg/l) }\end{array}$} & pH (-) after dilution to 40ppm \\
& Dry & Wet & Dry & Wet & Dry & Wet \\
\hline Bagusa & $199.5 \pm 16.4$ & $187.6 \pm 17.1$ & $3.2 \pm 0.8$ & $3.3 \pm 0.7$ & $10.5 \pm 0.4$ & $9.8 \pm 1.2$ \\
Murumuri & $162.8 \pm 25.5$ & $158.9 \pm 22.4$ & $1.7 \pm 0.5$ & $2.1 \pm 0.6$ & $11.1 \pm 1.3$ & $10.1 \pm 1.8$ \\
Katwe & $180 \pm 25.9$ & $167.8 \pm 23.5$ & $2.6 \pm 0.2$ & $2.9 \pm 0.1$ & $9.9 \pm 0.1$ & $9.1 \pm 0.3$ \\
Bunyampaka & $199.3 \pm 15.4$ & $189.6 \pm 16.2$ & $2.2 \pm 0.6$ & $2.3 \pm 0.4$ & $9.6 \pm 0.1$ & $9.2 \pm 0.4$ \\
Maseche & $102.3 \pm 11.7$ & $92.3 \pm 11.7$ & $2.9 \pm 0.4$ & $3.1 \pm 0.2$ & $10.9 \pm 0.5$ & $9.9 \pm 0.4$ \\
\hline
\end{tabular}

Values given in the table are means and standard deviations of the given parameters.

Table 2: Physical observations taken from the water samples of the different lakes in the hatching cones after 12 and 48 hours of aeration and incubation after inoculation of Artemia cysts.

\begin{tabular}{|c|c|c|c|c|c|}
\hline & Bagusa & Bunyampaka & Katwe & Omurumuri & Maseche \\
\hline $\begin{array}{l}\text { After } \\
24 \mathrm{hrs}\end{array}$ & $\begin{array}{l}\text {-Little foam } \\
\text { formed with cysts } \\
\text { well mixing } \\
\text {-no nauplii- } \\
\text { microscopic } \\
\text { examination }\end{array}$ & $\begin{array}{l}\text { - foam which hinder } \\
\text { cysts mixing } \\
\text {-no } \\
\text { microscopic } \\
\text { examination }\end{array}$ & $\begin{array}{l}\text {-Little foam cysts } \\
\text { well mixing } \\
\text {-no nauplii- } \\
\text { microscopic } \\
\text { examination }\end{array}$ & $\begin{array}{l}\text {-foam which } \\
\text { hinder cysts } \\
\text { mixing } \\
\text {-no nauplii - } \\
\text { microscopic } \\
\text { examination }\end{array}$ & $\begin{array}{l}\text { - foam which } \\
\text { hinder cysts } \\
\text { mixing } \\
\text {-no nauplii- } \\
\text { microscopic } \\
\text { examination }\end{array}$ \\
\hline $\begin{array}{l}\text { After } \\
48 \mathrm{hrs}\end{array}$ & $\begin{array}{ll}\text {-Nauplii } & -3 \\
\text { thoracopods } & \\
\text { (Instar I) } & \\
\text {-Some ciliates } & \\
\end{array}$ & $\begin{array}{l}\text { Nauplii } \quad-3 \\
\text { thoracopods (Instar I) } \\
\text {-Some ciliates }\end{array}$ & $\begin{array}{l}\text { Nauplii } \\
\text { thoracopods } \\
\text { (Instar I) } \\
\text {-Some ciliates }\end{array}$ & $\begin{array}{l}\text { Nauplii - } 3 \\
\text { thoracopods } \\
\text { (instar I) } \\
\text {-Some ciliates }\end{array}$ & $\begin{array}{l}\text { Nauplii }-3 \\
\text { thoracopods } \\
\text { (Instar I) } \\
\text {-Some ciliates }\end{array}$ \\
\hline
\end{tabular}

Table 3: Hatching Percentage of the different Artemia strains using the different water samples collected in dry and wet season after $48 \mathrm{hrs}$ of inoculation, aeration and incubation.

\begin{tabular}{llll}
\hline & & \multicolumn{2}{l}{ Hatching percentage (\%) at 48hrs } \\
\hline Artemia Strain & water sample & \multicolumn{2}{l}{ Season of collection } \\
& Dry & Wet \\
\hline GSL & Bagusa & $3.1 \pm 0.3$ & $9.8 \pm 1.2^{*}$ \\
& Kurumuri & $4.5 \pm 2.7$ & $4.8 \pm 2.4^{*}$ \\
& Katwe & $26.8 \pm 9.8$ & $30.0 \pm 9.9^{*}$ \\
Bunyampaka & $29.0 \pm 3.6$ & $27.8 \pm 4.0^{*}$ \\
PAS & Maseche & $29.3 \pm 4.3$ & $28.7 \pm 4.9^{*}$ \\
\cline { 2 - 4 } & Bagusa & $2.1 \pm 0.3$ & $2.3 \pm 0.8$ \\
& Murumuri & $0.3 \pm 0.6$ & $0.2 \pm 0.3$ \\
KUZ & Katwe & $1.3 \pm 1.5$ & $0.7 \pm 0.6$ \\
& Bunyampaka & $3.3 \pm 0.7$ & $1.7 \pm 2.0$ \\
& Maseche & $2.9 \pm 0.2$ & $2.5 \pm 0.7$ \\
\cline { 2 - 4 } Vagusa & $1.0 \pm 1.0$ & $1.3 \pm 0.3$ \\
& Murumuri & $0.7 \pm 1.3$ & $0.7 \pm 0.6$ \\
& Katwe & $0.7 \pm 1.2$ & $1.5 \pm 0.5$ \\
Bunyampaka & $0.4 \pm 0.7$ & $0.7 \pm 0.6$ \\
& Maseche & $1.1 \pm 1.1$ & $1.8 \pm 0.4$ \\
\cline { 2 - 4 } Chinese & Bagusa & $93.9 \pm 29.4$ & $79.8 \pm 15.2^{* * *}$ \\
& Murumuri & $65.1 \pm 10.0$ & $70.5 \pm 6.6^{* * *}$ \\
& Katwe & $89.3 \pm 6.9$ & $92.7 \pm 3.6^{* * *}$ \\
& Bunyampaka & $79.5 \pm 19.9$ & $82.2 \pm 11.4^{* * *}$ \\
& Maseche & $83.4 \pm 10.7$ & $83.5 \pm 9.1^{* * *}$ \\
\hline & Bagusa & $8.8 \pm 10.8$ & $12.1 \pm 7.3^{*}$ \\
& Murumuri & $9.8 \pm 5.7$ & $9.9 \pm 4.9^{*}$ \\
& Katwe & $33.0 \pm 8.2$ & $33.3 \pm 9.4^{*}$ \\
& Bunyampaka & $26.5 \pm 17.4$ & $26.5 \pm 17.4^{*}$ \\
& Maseche & $26.5 \pm 17.8$ & $26.1 \pm 16.6^{*}$ \\
\hline
\end{tabular}

Values are means and standard deviation of the three replicates. *indicates significant difference in hatching percentages between Artemia strains (P-value $<0.05)$. 